\title{
Serological biomarker testing helps avoiding unnecessary endoscopies in obese patients before bariatric surgery
}

\author{
Jaanus Suumann ${ }^{1}$, Toomas Sillakivi ${ }^{1 *} \mathbb{B}$, Živile Riispere ${ }^{2}$, Kari Syrjänen ${ }^{3}$, Pentti Sipponen ${ }^{4}$, Ülle Kirsimägi ${ }^{1}$
} and Ants Peetsalu ${ }^{1}$

\begin{abstract}
Background: To assess the value of serological biomarker testing as a substitute for esophagogastroduodenoscopy (EGDS) in pre-operative assessment of patients referred for bariatric surgery.

Methods: Sixty-five obese patients with a mean age of 43 years (range: 21-65) and a mean body mass index (BMI) of 44 (range: 36-59) were studied. The patients were tested with a four-biomarker panel: pepsinogen I and II, gastrin-17 (basal and stimulated), and Helicobacter pylori (HP) antibodies (GastroPanel${ }^{\oplus}$, Biohit Oyj, Finland). On the basis of the biomarker test, the patients were classified into the HS (healthy stomach) group $(n=22)$ with the normal biomarker profile and the NHS (non-healthy stomach) group $(n=43)$. The classification of patients into HS and NHS was evaluated against the gold standard, i.e. EGDS with biopsies.

Results: The concordance (Cohen's kappa) between the biomarker test and gastric histology was 0.68; 95\% Cl 0.504-0.854, with an overall agreement of $84.6 \%$ (95\% Cl 73.9-91.4\%). In the NHS group, all 43 patients had biopsy-confirmed chronic gastritis: 39 non-atrophic HP-gastritis, 4 atrophic antrum gastritis (AGA) of moderate severity. In the HS group only 6 patients had mild superficial H.pylori negative gastritis. Of the $22 \mathrm{HS}$ subjects with the normal biomarker profile, 20 (31\% of all 65) had no complaints either, while the remaining two had reflux symptoms with esophagitis. In the NHS group 10 patients had esophagitis and 8 had also reflux symptoms.

Conclusions: The normal biomarker profile is an excellent surrogate for healthy stomach, implicating that pre-operative EGDS could have been avoided in 31\% of our asymptomatic bariatric surgery patients who had the normal biomarker profile.
\end{abstract}

Keywords: Morbid obesity, Bariatric surgery, Gastroscopy, Serological biomarkers, Test accuracy, Histological evaluation, Sydney system (USS), GastroPanel

\section{Background}

Currently, overweight and obesity are a major priority in global healthcare, affecting over 600 million adults and the figures have more than doubled since 1980 [1-4]. Obesity is an independent risk factor for a variety of chronic diseases, including hiatal hernia, gastroesophageal reflux disease (GERD), erosive esophagitis, Barret's esophagus and esophageal adenocarcinoma [5-10].

During the past three decades, bariatric surgery has gained an increasingly important role in the management

* Correspondence: toomas.sillakivi@kliinikum.ee

'Department of Surgery, University of Tartu, Tartu, Estonia

Full list of author information is available at the end of the article of the most severe cases of obesity [4]. In the current clinical practice, esophagogastroduodenoscopy (EGDS) has been the gold standard in the preoperative investigation of all patients referred for bariatric surgery, but its routine use in asymptomatic patients has been questioned [10-14]. The opponents argue that preoperative EGDS findings rarely change surgical management [15-17]. However, there is unanimous agreement that all bariatric patients with upper gastrointestinal (UGI) complaints should undergo preoperative EGDS $[17,18]$. This is because bariatric operation includes surgery of the stomach, which makes accurate preoperative assessment important and contributes to the patient set-up and operation type. The question 
remains, however, whether systematic EGDS could be replaced by another (non-invasive) diagnostic tools in this setting.

During the past decade, the use of serological biomarker testing has gained increasing popularity as a non-invasive diagnostic tool for dyspeptic patients and asymptomatic subjects to diagnose both functional disorders and gastric diseases, including HP infection and atrophic gastritis (mucosal atrophy) (AG) [19]. The latest innovation in this technology represents a panel of 4 stomach-specific biomarkers (Pepsinogen I and II, Gastrin-17 and HP antibody) known as the GastroPanel ${ }^{\circ}$ test (Biohit, Oyj, Finland), which distinguishes between 8 diagnostic marker profiles [19]. Apart from the perfectly normal profile, three others represent purely functional disorders (in acid output) while the remaining four indicate morphological abnormalities (HP and AG). With its very high negative predictive value (>95\%), the normal marker profile excludes any significant gastric pathology with high probability. On the other hand, accurate diagnosis of the gastritis phenotype and topography (antrum or corpus) are important because of their different risks for gastric cancer and/or peptic ulcer [19]. Today the validity for GastroPanel to diagnose and delineate the healthy stomach and $H$. pylori gastritis with or without atrophy has already been confirmed in many independent clinical investigations against the gold standard (endoscopy with endoscopic histology); this issue has been adressed in at least two systematic reviews [20, 21].

The serological biomarker test is a non-invasive diagnostic tool which is substantially less expensive than EGDS (e.g. in Finland the cost of GP is about 125 EUR vs 600 EUR for gastroscopy with histopathological evaluation). On the basis of the GastroPanel test, it is straightforward to select patients for whom gastroscopy is mandatory, i.e. those with AG (antrum, corpus or both). In contrast, gastroscopy is not needed for patients who present with HP-infection alone (with no AG); conventional HP eradication is sufficient management [19]. Similarly, no additional information can be obtained by means of gastroscopy in those patients who have a normal marker profile, despite the fact that minor lesions (e.g. non-specific inflammation, mucosal irritation or micro-erosion) are not excluded by the normal marker profile.

Given the existing divergent opinions on the role of EGDS in the management algorithm of obese patients referred for bariatric surgery [10-18], we designed the present study to elucidate the role of non-invasive biomarker testing in the pre-operative evaluation of these patients. Using gastroscopy and biopsies as the gold standard, all patients were tested with GastroPanel $^{\odot}$ to establish the concordance between these two techniques. One of the aims was to evaluate the reliability of the normal marker profile (also called "healthy stomach", HS) to predict a biopsy-confirmed healthy gastric mucosa. This should have direct bearing with the key clinical question: how many EGDS examinations can be avoided by systematic biomarker testing of obese patients before bariatric surgery?

\section{Methods}

This study is a part of an ongoing prospective cohort study of 65 obese patients who underwent bariatric surgery at Tartu University Hospital. The key patient characteristics are presented in Table 1 . The mean age of the patients was 43.1 years (SD 9.1), and the mean BMI was 44.3 (SD 5.1). Of the 65 patients, $44(68 \%)$ were women. All patients were eligible for bariatric surgery: i.e., a BMI of $>40$ or $>35$, with certain obesity-related comorbidities. In accordance with the approved study design, all patients underwent the following pre-operative examinations: serum sampling for biomarker testing, recording the history of upper abdominal complaints (dyspepsia, heartburn), routine EGDS examination with directed biopsies, and their histological evaluation.

The serological biomarker test $\left(\right.$ GastroPanel $^{\odot}$ test, Biohit Oyj, Helsinki, Finland) follows the manufacturer's instructions, as previously detailed [20]. All samples were properly stored and transported to the service laboratory of Biohit Oyj for analysis.

\section{GastroPanel interpretation}

GastroPanel is an automated ELISA test that measures the plasma levels of the following biomarkers: Pepsinogen I (PgI) and II (PgII), fasting (basal) and stimulated amidated G17 (G17b and G17 s), HP antibodies (HPAb). The manufacturer-validated reference values of the four biomarkers were used: PgI 30-160 $\mu \mathrm{g} / \mathrm{l}$; PgII 3-15 $\mu \mathrm{g} / \mathrm{l}$; PgI/ PgII ratio 3-20, G17b 1-7 pmol/l; G17 s 3-30 pmol/l; $\mathrm{HPAb}<30 \mathrm{EIU}$ [22-24]. The results are interpreted, using

Table 1 Key characteristics of the patients

\begin{tabular}{ll}
\hline Patient characteristics & \\
\hline Age (years, mean \pm SD) & $43.1(9.08)$ \\
Females $n(\%)$ & $44(67.7)$ \\
Preoperative weight (kg, mean \pm SD) & $128.3(21.5)$ \\
Preoperative body mass index (Kg/m², mean \pm SD) & $44.3(5.12)$ \\
Concomitant diseases (any) $n(\%)$ & $57 / 65(87.7)$ \\
Type II diabetes $n(\%)$ & $9(13.8)$ \\
Hypertonia, cardiac disease $n(\%)$ & $39(60)$ \\
Obstructive sleep apnea $n(\%)$ & $20(30.7)$ \\
Degenerative joint disease $n(\%)$ & $13(20)$ \\
Hypercholesterolemia $n(\%)$ & $42(64.6)$ \\
Smokers $n(\%)$ & $17(26.1)$ \\
\hline
\end{tabular}


the special GastroSoft ${ }^{\bullet}$ software, by classifying the results according to the biomarkers levels into one of the five diagnostic categories: 1) normal profile, 2) superficial (HP) gastritis (PgI, PgII, PgI/PgII, G-17 Normal or High; HPAb $>30$ EIU), 3) atrophic gastritis of the antrum (AGA) (PgI, PgI/PgII Normal; G-17b Low; HPAb>30EIU), 4) atrophic gastritis of the corpus (AGC) (PgI, PgI/PgII Low; G-17b High; HPAb <30EIU or $>30 \mathrm{EIU})$, or 5) atrophic pangastritis (AG of the antrum and corpus) (AGP) (PgI Low, PgII Normal or Low; PgI/PgII Low, G-17b Low; HPAb $>30$ EIU), as detailed elsewhere [19, 23, 25].

\section{Esophagogastroduodenoscopy (EGDS)}

During EGDS, the esophageal, gastric and duodenal mucosa was visually inspected and abnormalities were detected. The degree of esophagitis was evaluated according to the Los Angeles classification (LA) [26]. In every patient, two biopsies from the antrum $(2 \mathrm{~cm}$ from the pyloric ring) and two biopsies from the corpus were collected. Additional biopsies were taken only when necessary. The histology of the biopsies was evaluated separately for the gastric antrum and corpus, according to the updated Sidney System (USS) classification [24], by 3 independent pathologists (ZR, KS, PS). In the case of discrepant results, the biopsies were re-evaluated by a pathologists' panel, and the consensus diagnosis was used as the final one. HP-colonization and its abundance were semi-quantitatively estimated, separately in the antral and corpus mucosa, by microscopic counting, as absent, mild, moderate and severe, as described earlier [27].

The classification of patients into the HS and NHS groups according to the Gastropanel results was evaluated against the gold standard, EGDS with biopsies.

\section{Statistical analysis}

For statistical analysis, the patients were divided into 2 groups: HS (healthy stomach) group (=normal GastroPanel profile) and NHS (non-healthy stomach) group (all abnormal profiles). All data were compared across these two groups. All statistical analyses were performed using the Statistica 13 software package. To evaluate the agreement between the gastric histology (USS) and the biomarker results (GastroPanel), regular Cohen's kappa test (with $95 \% \mathrm{CI}$ ) was used. Continuous variables were presented as mean values with standard deviation (SD) and categorical variables were presented as absolute and relative frequencies. The Chi-square and Fisher's exact tests were employed to assess differences in the categorical data. The nonparametric Mann-Whitney test was used to assess differences in the biomarker values across the study groups. All $P$ values were two-sided, a difference was considered statistically significant at $P<0.05$.

\section{Results}

Table 2 shows concordance between the GastroPanel test and USS histology (5 categories in both). Using the kappa test, agreement between the two methods was significant: Kappa $=0.68$ (95\% CI 0.504-0.854), with an overall agreement of 55/65 (84.6\%; 95\% CI 73.9-91.4\%) across 5 diagnostic categories.

Using the two-tier stratification (HS vs. NHS), based on biomarker testing, 22 (34\%) of the patients were classified into the HS (normal marker profile) group, and $43(66 \%)$ into the NHS group. The biomarker values in these two patient categories are shown in Table 3. Not unexpectedly, the biomarker values in the two groups were significantly different, all except for the PgI/PgII ratio that showed higher values in the NHS group.

The prevalence of HP infection in the entire cohort was $43 / 65(66 \%)$ in the GastroPanel test and 41/65 $(63 \%)$ in the histological evaluation of the biopsies. In the HS group $(n=22), 6 / 22(27 \%)$ patients had mild chronic HP-negative gastritis in the antrum or corpus, without intestinal metaplasia or substantial activity. There was no statistical difference in any of the biomarkers between these 6 patients (with minor histological findings) or in the remaining 16 patients in the HS group.

In the NHS group $(n=43)$, all patients had histologically confirmed chronic gastritis: 39 patients had non-atrophic HP- gastritis and 4 had AG. The HP- related chronic gastritis was detected as follows: in the antrum, mild or moderate gastritis in 36 cases and severe in 5 cases; in the corpus, mild or moderate gastritis in 36 cases and severe in 2 cases. Four patients had moderate degree AGA at histological evaluation. The G17b (1.6 pmol) and G-17 s ( $2.7 \mathrm{pmol} / \mathrm{l})$ were low in the first case and low also in the second case (G-17b 0.16 and G-17 s 1.97 pmol/l (over three-fold increase in G17 s but still below the 3 pmol threshold). In the other two cases of AGA, the G17 levels were normal (3.4/12 and 2.6/9.6 pmol/l, respectively, for G-17b and G-17 s, indicating a normal function of the antral $\mathrm{G}$ cells. In none of the cases, atrophy was detected in the gastric corpus mucosa (AGC).

In one patient, classified as a case of panatrophy by GP, the histological evaluation did not confirm the finding, i.e. $H$. pylori related chronic superficial gastritis: antrummoderate degree chronic gastritis with mild activity, mild degree $H$. pylori infection, no atrophy; corpus- moderate degree chronic gastritis with mild activity, mild degree $H$. pylori infection, no atrophy.

In the HS group, hiatal hernia was endoscopically diagnosed in 4 patients and 2 of them had reflux complaints with LA grade A and grade B esophagitis at EGDS. Three patients in the HS group had erosions at EGDS with a modified Lanza score [28] of 2, 2 and 3, 
Table 2 Concordance between the biomarker test results and histological diagnosis

\begin{tabular}{|c|c|c|c|c|c|c|c|}
\hline & Gastric mucosa $\mathrm{h}$ & ggy (USS & (cation $\left.{ }^{a}\right)$ & & & & \\
\hline \multirow[t]{7}{*}{$\begin{array}{l}\text { Diagnostic Categories of the } \\
\text { GastroPanel test }\end{array}$} & & Normal & $\begin{array}{l}\text { Superficial (HP) } \\
\text { Gastritis }\end{array}$ & $\begin{array}{l}\text { Antral } \\
\text { atrophy } \\
\text { (AGA) }\end{array}$ & $\begin{array}{l}\text { Corpus } \\
\text { atrophy } \\
\text { (AGC) }\end{array}$ & $\begin{array}{l}\text { Panatrophy } \\
\text { (AGP) }\end{array}$ & Total \\
\hline & Normal profile & 16 & 6 & 0 & 0 & 0 & 22 \\
\hline & $\begin{array}{l}\text { Superficial (HP) } \\
\text { Gastritis }\end{array}$ & 0 & 38 & 3 & 0 & 0 & 41 \\
\hline & Antral atrophy & 0 & 0 & 1 & 0 & 0 & 1 \\
\hline & Corpus atrophy & 0 & 0 & 0 & 0 & 0 & 0 \\
\hline & Panatrophy & 0 & 1 & 0 & 0 & 0 & 1 \\
\hline & Total & 16 & 45 & 4 & 0 & 0 & 65 \\
\hline
\end{tabular}

${ }^{a}$ The Updated Sydney System (USS) classification of gastritis

respectively. All these 3 patients with erosions were HPnegative, with PgII levels of $3.8,3.4$ and $3.8 \mu \mathrm{g} / \mathrm{l}$, i.e., with no increase in this mucosal inflammation marker. They all used multiple medications (cardiac, glucocorticoids etc.) due to comorbidities.

Table 4 summarizes the clinical (endoscopic) findings in the HS and NHS groups. Importantly, 20/65 patients (31\%), all from the HS group, had no clinical symptoms or HP-associated gastritis, and their biomarker profile was also normal.

In the NHS group, hiatal hernia was endoscopically confirmed in $15 / 43$ patients and esophagitis in 10/43 patients, while 8 had reflux complaints. Only 2 of the 10 patients with esophagitis had G17b levels below 1 pmol/l ( 0.75 and $0.16)$; the remaining 8 had the G-17b levels between $1.6 \mathrm{pmol} / \mathrm{l}$ and $13.9 \mathrm{pmol} / \mathrm{l}$. In 4 patients with reflux symptoms, esophagitis was confirmed on EGDS: LA grade A in 3 patients and Grade B in 1 patient. In the NHS group, 14 patients also had erosions /erosive gastritis and 1 patient had incidental duodenal polyp. In the NHS group (with 14 patients having erosions), the mean PgII levels were almost three times as high as those in the HS group (Table 3).

There was no correlation between G17b and esophagitis at EGDS or between G17b levels and GERD complaints irrespective of the fact whether patients belonged to the HS or NHS group (all $\mathrm{p}=\mathrm{NS}$ ).

\section{Discussion}

According to the gastric biomarker test results, our patients were divided into the HS and NHS groups, following previous suggestions [19]. Using gastroscopic biopsies as the gold standard, the concordance between the biomarker testing and histology was substantial, with a kappa value of 0.68 and an overall agreement (across 5 categories) of $84.6 \%$. These values favourably compete with those reported in previous validation studies $[19,23]$. This is not unexpected because the biomarker test used (GastroPanel) is based on four biomarkers reflecting the

Table 3 The biomarker levels in the two categories (HS/NHS) of patients

\begin{tabular}{|c|c|c|c|c|}
\hline & Whole Series & $\begin{array}{l}\text { Healthy stomach } \\
\text { (HS Group) } \\
n=22\end{array}$ & $\begin{array}{l}\text { Non-healthy stomach } \\
\text { (NHS Group) } \\
n=43\end{array}$ & ( $p$-value)\# \\
\hline${ }^{\mathrm{a} G 17 b}$ pmol/l mean \pm SD (range) & $\begin{array}{l}3.9 \pm 5.0 \\
(0-28.1)\end{array}$ & $\begin{array}{l}2.05 \pm 2.2 \\
(0-9.9)\end{array}$ & $\begin{array}{l}4.9 \pm 5.7 \\
(0-28.1)\end{array}$ & 0.028 \\
\hline${ }^{\mathrm{b}} \mathrm{G} 17$ s pmol/I mean \pm SD (range) & $\begin{array}{l}12.3 \pm 10.3 \\
(0-40.9)\end{array}$ & $\begin{array}{l}8.8 \pm 8.4 \\
(0.2-36.1)\end{array}$ & $\begin{array}{l}14.1 \pm 10.8 \\
(0-40.9)\end{array}$ & 0.048 \\
\hline PG I $\mu g / l$ mean $\pm S D$ (range) & $\begin{array}{l}81.8 \pm 38.6 \\
(22.7-197.5)\end{array}$ & $\begin{array}{l}58.2 \pm 27.9 \\
(33.0-151.1)\end{array}$ & $\begin{array}{l}93.9 \pm 38.0 \\
(22.7-197.5)\end{array}$ & $<0.0001$ \\
\hline PG II $\mu \mathrm{g} / \mathrm{l}$ mean $\pm \mathrm{SD}$ (range) & $\begin{array}{l}7.2 \pm 5.9 \\
(0.3-29.3)\end{array}$ & $\begin{array}{l}3.37 \pm 1.7 \\
(0.3-8.4)\end{array}$ & $\begin{array}{l}9.2 \pm 6.4 \\
(1.4-29.3)\end{array}$ & $<0.0001$ \\
\hline PG I/PG II mean $\pm S D$ (range) & $\begin{array}{l}15.5 \pm 12.3 \\
(3.3-103.3)\end{array}$ & $\begin{array}{l}21.6 \pm 18.9 \\
(10.7-103.3)\end{array}$ & $\begin{array}{l}12.4 \pm 4.6 \\
(3.2-25.2)\end{array}$ & $<0.0001$ \\
\hline IgG EIU mean \pm SD (range) & $\begin{array}{l}64.2 \pm 40.8 \\
(2.1-121.1)\end{array}$ & $\begin{array}{l}13.12 \pm 7.7 \\
(2.1-27.3)\end{array}$ & $\begin{array}{l}90.4 \pm 21.1 \\
(38.1-121.1)\end{array}$ & $<0.0001$ \\
\hline
\end{tabular}

${ }^{a} \mathrm{G}-17 \mathrm{~b}$, basal gastrin-17

${ }^{b}$ G-17 s, stimulated gastrin-17

\#Mann-Whitney U-Test 
Table 4 Endoscopic findings, clinical symptoms in the pre-operative assessment of the HS and NHS groups

\begin{tabular}{lll}
\hline & $\begin{array}{l}\text { Healthy stomach } \\
\text { (HS Group) } \\
\mathrm{n}=22\end{array}$ & $\begin{array}{l}\text { Non-healthy } \\
\text { stomach } \\
\text { (NHS Group) } \\
n=43\end{array}$ \\
\hline $\begin{array}{lll}\text { Endoscopic findings: } \\
\text { - Hiatal hernia }\end{array}$ & 4 & 15 \\
- Esophagitis & 4 & 10 \\
- Erosions/erosive gastritis & 3 & 14 \\
- Duodenal polyp & - & 1 \\
Clinical symptoms: & & 8 \\
- Reflux disease (GERD) & 2 & \\
\hline
\end{tabular}

GERD gastroesophageal reflux disease

function and structural integrity of the stomach mucosa $[19,22,23,25,29]$. Accordingly, Pepsinogen levels and their ratio are decreased in corpus atrophy, accompanied by elevated G-17. The G-17 level also gives indication of gastric acid secretion, being low with high acid output and high when stomach is acid-free (due to PPI treatment or AG). In antrum atrophy, G-17 is low and does not respond to protein stimulation (lack of G-cells). The two main indications of the GastroPanel test are: 1) first-line diagnostic test for dyspeptic complaints, and 2) screening of asymptomatic subjects for gastric cancer risk (HP and AG). Despite the fact that some minor abnormalities are not detected by the normal marker profile, GastroPanel is a test for stomach health, with an excellent longitudinal negative predictive value. On the other hand, abnormal test results implicating AG do predict a significantly increased long-term risk for gastric cancer.

The present study is the first where the utility of this biomarker test in the pre-operative management of bariatric surgery patients was evaluated in a $100 \%$ biopsyconfirmed clinical setting. One of the aims was to assess how many gastroscopies could be avoided by using the normal biomarker profile as a surrogate for healthy stomach (HS). The results are encouraging, while implicating that using this approach, the HS and NHS groups can be distinguished with high accuracy. Indeed, the serum levels of all 4 biomarkers were significantly different in the HS and NHS groups, being markedly higher in the latter (Table 3). Most remarkably, the markers of mucosal inflammation (PgII in particular) was almost three times as high in the NHS patients as in the HS patients.

HP is the key causative factor of severe gastric pathology, including peptic ulcer disease and gastric cancer. In the study cohort, the prevalence (66\%) of HP in candidates for bariatric operation was significantly higher than that reported in many previous studies (3.4-17\%) from Belgium, Finland and the USA $[13,15,30]$, but similar to that (53-66\%) reported from Greece and Brazil [31-33]. In the Estonian population, HP prevalence is closely associated with the birth cohort [34, 35]: HP has become more rare among younger generations. In our bariatric surgery cohort, the detected $66 \%$ prevalence of HP is equivalent to that (56-69\%) reported in previous studies on the same birth cohorts (1970-1990) of the general population in Estonia [35].

Because HP is associated with severe clinical sequels $[19,36-38]$, its eradication is indicated [13] and leads to regression of the inflammatory process in the gastric mucosa and significantly reduces the risk for its known complications at the population's level. Indeed, the reported preoperative endoscopic findings (hiatal hernia, 16-25\%; esophagitis, 13-30\%) from geographic regions with low HP prevalence $[13,15,30]$, as well as from the the high-prevalence regions [31-33], are consistent with similar morbidity in our cohort (Table 4). Chronic inflammation of the stomach mucosa was detected in 75\% (49/65) and atrophy in $6.2 \%(4 / 65)$ of the patients. As expected, gastric diseases (gastritis, 65.1\%; AG, 16.7\%) are more frequent in regions [31,33] with high HP prevalence, like Estonia, as compared with the low-prevalence regions (gastritis, 9.128\%; AG 0.9\%) [13, 15, 30].

Most of the patients in the NHS group had HP -related gastritis without atrophy. In such cases, gastroscopy is optional if the patient requests it [19]. Gastroscopy is mandatory only in the cases with suspected AG or in patients with sustained symptoms. In the NHS group, only four patients had moderate AGA which requires regular monitoring by endoscopy to disclose eventual progression and increased risk of gastric cancer [37, 39]. Of these four AGA cases, only one was clearly confirmed and another one was suspected on the basis of biomarker testing. In the other two cases, AGA was only confirmed with biopsy. In GastroPanel, the G-17 values were within normal limits, implicating that abundant G-cells were still present to sustain the normal G-17 output. Most likely, these cases represent patchy mucosal atrophy instead of a diffuse disease. It is not well established how such patchy atrophy behaves in the long run, and whether regular endoscopic monitoring is indicated or whether biomarker testing is sufficient. It is likely that the gastric mucosa in these patients can significantly recover after HP eradication, while inflammation symptoms diminish or disappear and the process of mucosal atrophy can be arrested, as reported earlier [24, 39, 40].

In our series, AGA detected by the biomarkers was rare, which has been shown before [41]. A recent meta-/ analysis of the published GastroPanel literature confirmed that the test works better for detection of AGC (PgI, PgI/PgII ratio) than AGA (G-17). A simple explanation is that low G-17 levels can result from two distinct causes: AGA and high acid output [19, 20, 42]. No biomarker that is 
regulated by more than one trigger can be a highly specific indicator of only the other [20]. To make distinction between these two (AGA, high acid output), it is mandatory to test G-17 after protein stimulation (G-17 s). Failure to increase G17 s output implicates lack of G-cells and presence of AGA [20].

Another explanation for the rarity of AGA in our series could be the relatively young age of the patients. In fact, GastroPanel was not primarily designed for testing bariatric surgery patients but for diagnosis and screening of elderly patients with AG and for screening increased risk of gastric cancer [29]. However, bariatric surgery can be safely performed also in patients aged 60 years or more [43]. In this sub-group, the potential role of the gastric biomarker test can be particularly important as the incidence of atrophy and gastric cancer increases with age. Furthermore, using the biomarker test, we could easily diagnose almost all HP-infections and administer a timely treatment to diminish the risk of AG and gastric cancer.

There was also one false positive "panatrophy" (according to GP) in our series while histologically only superficial H.pylori related gastritis was confirmed. Rather, this fact could be related to technical issues.

In patients with AG, follow-up EGDS is still needed. Thus the gastric sleeve method (SG) would be preferable, because routine EGDS after bypass operation (GBP) is unfeasible. In large series of operated patients, however, practically no post-operative problems have been reported in the bypass group. Only a few case reports are available on postoperative cancer [44].

Regarding the use of the normal GastroPanel profile as a surrogate for healthy stomach (HS), 22/65 subjects were categorised into this group according to its criteria. Clinically, 20 of them were asymptomatic, had no history of abdominal complaints, and only 2 had reflux symptoms. On EGDS, only minor abnormalities were detected that were considered clinically insignificant: non-HP gastritis, mild or moderate degree esophagitis, or gastric mucosa erosions. It is clear that management of these disorders does not require a delay in elective surgery, nor is it a contraindication for operation [11]. In 4 cases, esophagitis (LA grade $\mathrm{A} / \mathrm{B}$ ) was found to be associated with hiatal hernia, and 2 of these reported reflux complaints. According to international consensus $[17,18]$, for patients with upper abdominal complaints, endoscopic investigation is indicated. In patients with symptomatic esophagitis, the recommended surgical procedure could be gastric bypass rather than gastric sleeve. Although the opinions on the use of gastric sleeve in esophagitis are controversial [45], the probability of complicated esophagitis has been shown to increase postoperatively [46]. Such cases respond poorly to medical treatment [47], despite the fact that a major portion of the gastric corpus is resected, which results in a significant reduction of parietal cell mass and a decline in acid output.

There is yet no unanimous agreement on the need and technical methods for simultaneous gastric sleeve and hiatal hernia repair, although most authors agree that posterior hiatus repair is necessary when hiatal hernia is diagnosed pre- or intraoperatively $[47,48]$. It has been shown earlier that low basal G-17 levels in the general population are a marker of high basal acid output, which in turn predisposes to gastric acid reflux and esophagitis [42]. In this series, however, we failed to find correlation between esophagitis and low G17b levels, as only one out of the 4 patients in the HS group and 2/10 in the NHS group showed G-17b levels below the cut-off value. Although some studies have obtained results similar to ours $[49,50]$, there are also reports about such correlation between G-17 and esophagitis [51].

In the light of the above data, it is evident that in symptomatic esophagitis, endoscopy plays a role also in guiding the selection of the surgical method (i.e., preferring gastric bypass over gastric sleeve), which is crucial to ensure optimal treatment outcome. In our series, 3 asymptomatic patients in the HS group had, despite the normal marker profile, erosions in the stomach (antrum), with a Lanza score of less than 4 (i.e. not severe). Recently, some authors have reported gastric erosions in bariatric surgery patients [48] and others have reported them also in asymptomatic volunteers in population studies, more frequently in HP-negative than HPpositive subjects [40]. Although the cause of such erosions may be multifactorial, all 3 patients in our study took several medications known to damage the gastric mucosa. Yet the erosions seen in the HS group can be considered clinically insignificant: the patients were asymptomatic, and no complications like haemorrhage were found on EGDS. Accordingly, we cannot consider minor erosions in patients with the normal biomarker profile as an indication for changing treatment practices in such bariatric surgery patients.

Summing up for the HS group, our data demonstrate that the gastric biomarker test can definitely help select this particular patient group of asymptomatic patients (20/22 in this series) with minor but clinically nonsignificant gastric mucosa alterations for whom preoperative endoscopic investigation can be safely replaced by the non-invasive biomarker test. Endoscopy should only be reserved for symptomatic patients to confirm the diagnosis and opt for the surgical method, as has been pointed out earlier [17, 18].

Regarding the NHS patients, the rationale should be the same as for the HS patients: those with reflux complaints should undergo endoscopic investigation to confirm the diagnosis and to plan possible preoperative treatment. 
Endoscopic findings in bariatric surgery patients can be highly variable [52]. To avoid postoperative complications, including ulcer [52], it is important to evaluate the patients pre-operatively to detect (by using GastroPanel) [19] and eradicate HP infection. Although there were no cases of ulcer disease in our material, these steps are always important in this special group of patients. In the case of suspected peptic ulcer, EGDS is essential; the same applies to patients with a family history of gastric cancer.

The present results confirm that the normal biomarker profile in the GastroPanel test is an excellent surrogate for healthy stomach, and this non-invasive test could replace EGDS in the pre-operative management of bariatric surgery patients. Indeed, using the biomarker test, it could have been possible to avoid EGDS in 20/22 patients in the HS group, i.e., in $31 \%$ (20/65) of all bariatric patients in our cohort. These asymptomatic patients with the normal biomarker profile are at very low risk to develop a clinically significant disease in the gastric mucosa, including peptic ulcer and gastric cancer $[19,53]$.

\section{Conclusions}

The present study demonstrates good correlation between serum biomarkers and gastric mucosal status in preoperative assessment of bariatric surgery patients. In asymptomatic patients with the normal biomarker profile, endoscopic investigation can be safely abandoned, which brings significant economic and resource-related benefits. The potential cost-effectiveness of this strategy would also be population and country specific. Given the key causative role of HP in gastric pathologies, one can anticipate that the lower is HP prevalence in the population, the higher is the proportion of patients in whom EGDS can be avoided. The full benefits of the non-invasive biomarker screening of bariatric surgery patients for EGDS (high-risk patients only) can only be established in larger cohorts, with participants from different populations and with different prevalences of HPinfection.

\section{Abbreviations \\ AG: Atrophic gastritis (mucosal atrophy); AGA: Atrophic antrum gastritis; AGC: Atrophic gastritis of the corpus; AGP: Atrophic pan-gastritis (AG of the antrum and corpus); BMl: Body mass index; \\ EGDS: Esophagogastroduodenoscopy; G17 s: Stimulated amidated Gastrin 17; G17b: Basal (fasting) Gastrin 17: GBP: Gastric bypass; GERD: Gastroesophageal reflux disease; HP: Helicobacter pylori; HPAb: Helicobacter pylori antibodies; HS: Healthy stomach; LA: Los Angeles classification of esophagitis; NHS: Non- healthy stomach; Pgl: Pepsinogen I; Pgll: Pepsinogen II; SG: Sleeve gastrectomy; UGI: Upper gastrointestinal; USS: Updated Sidney System}

\section{Acknowledgements}

We thank Ester Jaigma for revising the English text of the manuscript.

\section{Funding}

The clinical part of the study was financed by the Faculty of Medicine, University of Tartu.
Availability of data and materials

The datasets used and/or analysed during the current study are available from the corresponding author at reasonable request.

\section{Authors' contributions}

$J S, T S, A P, K S$ and PS participated in the design of the study, interpreted the data, and drafted the manuscript. JS and TS collected the clinical material. $Z R, K S$ and PS performed, each independently, the histological evaluation of the gastric biopsies. ÜK designed and performed the statistical analyses. All authors have read and approved the final version of the manuscript.

\section{Ethics approval and consent to participate}

The study was approved by the Ethics Committee on Human Research of the University of Tartu. Written informed consent was obtained from all patients.

\section{Consent for publication}

Not applicable

\section{Competing interests}

K. Syrjänen is an employee of Biohit Oyj and participated in the study within part of his assignments as the Chief Medical Director of the company. He is not a shareholder of the company. Pentti Sipponen is a shareholder and member of the Scientific Advisory Board of Biohit Oyj. The company develops and markets laboratory tests mainly for gastrointestinal diseases. All other authors have no conflict of interest to report.

\section{Publisher's Note}

Springer Nature remains neutral with regard to jurisdictional claims in published maps and institutional affiliations.

\section{Author details}

${ }^{1}$ Department of Surgery, University of Tartu, Tartu, Estonia. ${ }^{2}$ Department of Pathology, University of Tartu, Tartu, Estonia. ${ }^{3}$ Department of Clinical Research, Biohit Oyj, Helsinki, Finland. ${ }^{4}$ Patolab Oy, Espoo, Finland.

Received: 22 August 2017 Accepted: 1 February 2018

Published online: 20 February 2018

\section{References}

1. Ogden CL, Carroll MD, Curtin LR, McDowell MA, Tabak CJ, Flegal KM. Prevalence of overweight and obesity in the United States, 1999-2004 JAMA. 2006:295(13):1549-55.

2. Benotti PN, Forse RA. The role of gastric surgery in the multidistsiplinary management of severe obesity. Am J Surg. 1995;169:361-7.

3. WHO http://www.who.int/mediacentre/factsheets/fs311/en/. Accessed 20 Apr 2017

4. Azagury DE, Lautz DB. Obesity overview: epidemiology, health and financial impact, and quidelines for qualification for surgical therapy. Gastrointest Endosc Clin Am. 2011;21:189-201.

5. Gu W, Chen C, Zhao KN. Obesity-associated endometrial and cervical cancers. Front Biosci (Elite Ed). 2013:5:109-18.

6. Aleksandrova K, Nimptsch K, Pischon T. Obesity and colorectal cancer. Front Biosci (Elite Ed). 2013:5:61-77.

7. Cheraghi Z, Poorolajal J, Hashem T, Esmailnasab N, Doosti IA. Effect of body mass index on breast cancer during premenopausal and postmenopausal periods: a meta-analysis. PLoS One. 2012;7:e51446.

8. Allott EH, Masko EM, Freedland SJ. Obesity and prostate cancer: weighing the evidence. Eur Urol. 2013;63:800-9.

9. Preston $\mathrm{SH}$, Mehta NK, Stokes A. Modeling obesity histories in cohort analyses of health and mortality. Epidemiology. 2013;24:158-66.

10. Gerson LB. Impact of obesity on endoscopy. Gastrointest Endosc. 2009;70:758-62.

11. Parikh M, Liu J, Vieira D, Tzimas D, Horwitz D, Antony A, Saunders JK, Ude-Welcome A, Goodman A. Preoperative endoscopy prior to bariatric surgery: a systematic review and meta-analysis of the literature. Obes Surg. 2016;26(12):2961-6.

12. Csendes A, Burgos AM, Smok G, Beltran M. Endoscopic and histologic findings of the foregut in 426 patients with morbid obesity. Obes Surg. 2007;1:28-34 
13. D'Hondt M, Steverlynck M, Pottel H, George C, Vansteenkiste F, Van Rooy F, Devriendt D. Value of preoperative EGD in morbidly obese patients undergoing laparoscopic roux-en-Y gastric bypass. Acta Chir Belg. 2013; 113(4):249-53.

14. Almazeedi S, Al-Sabah S, Al-Mulla A, Al-Murad A, Al-Mossawi A, Al-Enezi K, Jumaa T, Bastaki W. Gastric histopathologies in patients undergoing sleeve gastrectomies. Obes Surg. 2013;23(3):314-9. https://doi.org/10.1007/s11695012-0821-y.

15. Peromaa-Haavisto $\mathrm{P}$, Victorzon M. Is routine preoperative upper $\mathrm{Gl}$ endoscopy needed prior to gastric bypass? Obes Surg. 2013;23(6):736-9.

16. Schigt A, Coblijn U, Lagarde $S$, Kuiken S, Scholten $P$, van Wagensveld B. IS esophagogastroduodenoscopy before roux-en-Y gastric bypass or sleeve gastrectomy mandatory? Surg Obes Relat Dis. 2014;10(3):411-7. quiz 565-6

17. Anderson MA, Gan SI, Fanelli RD, Baron TH, Banerjee S, Cash BD, Dorminitz JA, Harrison ME, Ikenberry SO, Jagannah SB, Lichtenstein DR, Shen B, Lee KK, Van Guilder T, Stewart LE. Role of endoscopy in the bariatric surgery patient. Gastrointest Endosc. 2008;68(1):1-10.

18. Parkin DM. International variation. Oncogene. 2004;23:6329-40.

19. Agreus L, Kuipers EJ, Kupcinskas L, Malfertheiner P, Di Mario F, Leja M, Mahachai V, Yaron N, van Oijen M, Perez Perez G, Rugge M, Ronkainen J, Salaspuro M, Sipponen P, Sugano K, Sung J. Rationale in diagnosis and screening of atrophic gastritis with stomach-specific plasma biomarkers. Scand J Gastroenterol. 2012;47(2):136-47.

20. Syrjänen K. A panel of serum biomarkers (GastroPanel ${ }^{\circledR}$ ) in non-invasive diagnosis of atrophic gastritis. Systematic review and meta-analysis. Anticancer Res. 2016;36(10):5133-44.

21. Zagari RM, Rabitti S, Greenwood DC, Eusebi LH, Vestito A, Bazzoli F. Systematic review with meta-analysis: diagnostic performance of the combination of pepsinogen, gastrin-17 and anti-helicobacter pylori antibodies serum assays for the diagnosis of atrophic gastritis. Aliment Pharmacol Ther. 2017:1-11. https://doi.org/10.1111/apt.14248.

22. Sillakivi T, Suumann J, Kirsimägi U, Peetsalu A. Plasma levels of gastric biomarkers in patients after bariatric surgery: biomarkers after bariatric surgery. Hepatogastroenterol. 2013;60(128):2129-32.

23. Storskrubb T, Aro P, Ronkainen J, Sipponen P, Nyhlin H, Talley NJ, Engstrand L, Stolte M, Vieth M, Walker M, Agreus L. Serum biomarkers provide an accurate method for diagnosis of atrophic gastritis in a general population: the Kalixanda study. Scand J Gastroenterol. 2008;43(12):1448-55.

24. Dixon MF, Genta RM, Yardley JH, Correa P. Classification and grading of gastritis. The update Sidney system. Am J Surg Pathol. 1996;20:1161-81.

25. Sipponen P, Graham DY. Importance of atrophic gastritis in diagnostics and prevention of gastric cancer: application of plasma biomarkers. Scand J Gastroenterol. 2007 Jan;42(1):2-10.

26. Armstrong D, Bennett JR, Blum AL, Dent J, De Dombal FT, Galmiche JP, Lundell L, Margulies M, Richter JE, Spechler SJ, Tytgat GN, Wallin L. The endoscopic assessment of esophagitis: a progress report on observer agreement. Gastroenterology. 1996;111(1):85-92.

27. Stolte M, Eidt S, Ritter M, Bethke B. Campylobacter pylori and gastritis. Pathologe. 1989;10:21-6.

28. Lanza FL, Graham DY, Davis RE, Rack MF. Endoscopic comparison of cimetidine and sucralfate for prevention of naproxen-induced acute gastroduodenal injury. Effect of scoring method. Dig Dis Sci. 1990;35:1494-9.

29. Telaranta-Keerie A, Kara R, Paloheimo L, Härkönen M, Sipponen P. Prevalence of undiagnosed advanced atrophic corpus gastritis in Finland: an observational study among 4,256 volunteers without specific complaints. Scand J Gastroenterol. 2010;45(9):1036-41. https://doi.org/10.3109/00365521. 2010.487918.

30. Gomez V, Bhalla R, Heckman MG, Florit PT, Diehl NN, Rawal B, Lynch SA, Loeb DS. Routine screening endoscopy before bariatric surgery: is it necessary? Bariatr Surg Pract Patient Care. 2014;9(4):143-9.

31. Papavramidis ST, Theocharidis AJ, Zaraboukas TG, Christoforidou BP, Kessissoglou II, Aidonopoulos AP. Upper gastrointestinal endoscopic and histologic findings before and after vertical banded gastroplasty. Surg Endosc. 1996;10(8):825-30.

32. Assef MS, Melo TT, Araki O, Marioni F. Evaluation of upper gastrointestinal endoscopy in patients undergoing bariatric surgery. Arq Bras Cir Dig. 2015; 28(Suppl 1):39-42. https://doi.org/10.1590/S0102-6720201500S100012.

33. Dietz J, Ulbrich-Kulcynski JM, Souto KE, Meinhardt NG. Prevalence of upper digestive endoscopy and gastric histopathology findings in morbidely obese patients. Arq Gastroenterol. 2012;49(1):52-5.
34. Oona M, Utt M, Nilsson I, Uibo O, Vorobjova T, Maaroos HI. Helicobacter pylori infection in children in Estonia: decreasing Seroprevalence during the 11-year period of profound socioeconomic changes. Helicobacter. 2004;9:233-41.

35. Vorobjova T, Grünberg H, Oona M, et al. Seropositivity to helicobacter pylori and CagA protein in schoolchildren of different ages living in urban and rural areas in southern Estonia. Eur J Gastroenterol Hepatol. 2000;12:97-101.

36. Shrestha R, Koirala K, Raj KC, Batajoo KH. Helicobacter pylori infection among patients with upper gastrointestinal symptoms: prevalence and relation to endoscopy diagnosis and histopathology. J Family Med Prim Care. 2014;3(2):154-8. https://doi.org/10.4103/2249-4863.137663.

37. Nomura A, Stemmermann GN, Chyou PH, Kato I, Perez-Perez Gl, Blaser MJ. Helicobacter pylori infection and gastric carcinoma among Japanese Americans in Hawaii. N Engl J Med. 1991;325:1132-6.28.

38. Peleteiro B, Bastos A, Ferro A, Lunet N. Prevalence of helicobacter pulori infection worldwide: a systematic review of studies with national coverage. Dig Dis Sci. 2014;59(8):1698-709. https://doi.org/10.1007/s10620-014-3063-0. Epub 2014 Feb 22

39. Benotti PN, Forse RA. The role of gastric surgery in the multidisciplinary management of severe obesity. Am J Surg. 1995;169:361-7.

40. Lehmann FS, Renner EL, Meyer-Wyss B, Wilder-Smith CH, Mazzucchelli L, Ruchti C, Drewe J, Beglinger C, Merki HS. Helicobacter pylori and gastric erosions. Results of a prevalence study in asymptomatic volunteers. Digestion. 2000;62(2-3):82-6.

41. Graham DY, Nurgalieva ZZ, El-Zimaity HM, Opekun AR, Campos A, Guerrero L, Chavez A, Cardenas V. Noninvasive versus histologic detection of gastric atrophy in a Hispanic population in North America. Clin Gastroenterol Hepatol. 2006;4(3):306-14.

42. Sipponen P, Vauhkonen M, Helske T, Kaariainen I, Harkonen M. Low circulating levels of gastrin-17 in patients with Barrett's esophagus. World J Gastroenterol. 2005;11(38):5988-92.

43. Giordano S, Victorzon M. Bariatric surgery in elderly patients: a systematic review. Clin Interv Aging. 2015;10:1627-3513.

44. Gentileschi P, Gagner M, Milone L, Kini S, Fukuyama S. Histologic studies of the bypassed stomach after roux-en-Y gastric bypass in a porcine model. Obes Surg. 2006;16:886-90.

45. Hawasli A, Reyes M, Hare B, Meguid A, Harriott A, Almahmeed T, Thatimatla N, Szpunar S. Can morbidly obese patients with reflux be offered laparoscopic sleeve gastrectomy? A case report of 40 patients. Am J Surg. 2016;211(3):571-6. https://doi.org/10.1016/j.amjsurg.2015.11.006. Epub 2015 Dec 23

46. Melissas J, Braghetto I, Molina JC, Silecchia G, lossa A, lannelli A, Foletto M. Gastroesophageal reflux disease and sleeve gastrectomy. Obes Surg. 2015; 25(12):2430-5. https://doi.org/10.1007/s11695-015-1906-1.

47. Stenard F, lannelli A. Laparoscopic sleeve gastrectomy and gastroesophageal reflux. World J Gastroenterol. 2015;21(36):10348-57. https://doi.org/10.3748/wjg.v21.i36.10348.

48. Mahawar KK, Carr WR, Jennings N, Balupuri S, Small PK. Simultaneous sleeve gastrectomy and hiatus hernia repair: a systematic review. Obes Surg. 2015; 25(1):159-66. https://doi.org/10.1007/s11695-014-1470-0.

49. Monkemuller K, Neumann H, Nocon M, Vieth M, Labenz J, Willich SN, Stolte $M$, Hocker $M$, Jaspersen $D$, Lind T, Malfertheiner P. Serum gastrin and pepsinogens do not correlate with the different grades of severity of gastro-oesophageal reflux disease: a matched case-control study. Aliment Pharmacol Ther. 2008;28(4):491-6. https://doi.org/10.1111/j.1365-2036.2008. 03769.x. Epub 2008 Jun 16

50. Peitz U, Wex T, Vieth M, Stolte M, Willich S, Labenz J, Jaspersen D, Lind T, Malfertheiner $P$. Correlation of serum pepsinogens and gastrin-17 with atrophic gastritis in gastroesophageal reflux patients: a matched-pairs study. J Gastroenterol Hepatol. 2011;26(1):82-9. https:/doi.org/10.1111/j.1440-1746.2010.06413.x.

51. Goni E, Ricco M, Franceschi M, Baldassarre G, Panozzo MP, Antico A, De Bastiani R, Scarpignato C, Di Mario F. Gastrin 17 as non invasive marker of reflux disease. Dig Liver Dis. 2015;47(S1):e164-5.

52. Fernandes SR, Meireles LC, Carrilho-Ribeiro L, Velosa J. The role of routine upper gastrointestinal endoscopy before bariatric surgery. Obes Surg. 2016; 26(9):2105-10. https://doi.org/10.1007/s11695-016-2056-9.

53. Sipponen $\mathrm{P}, \mathrm{Hy}$ ärinen $\mathrm{H}$. Role of helicobacter pylori in the pathogenesis of gastritis, peptic ulcer and gastric cancer. Scand J Gastroenterol Suppl. 1993;196:3-6. 